\title{
Production and Regulation of Extracellular Endocellulase by Agaricus bisporus
}

\author{
By K. MANNING* AND D. A. WOOD \\ Glasshouse Crops Research Institute, Rustington, Littlehampton, \\ West Sussex BN16 3PU, U.K.
}

(Received 17 December 1982)

\begin{abstract}
Extracellular endocellulase production by Agaricus bisporus closely paralleled mycelial growth in cultures containing microcrystalline cellulose. The enzyme was induced by various celluloses and cellobiose. In the presence of a cellulose inducer glucose and cellobiose repressed production of the enzyme. Endocellulase activity in culture filtrates was inversely related to cellulose concentration in the culture. In high concentrations of cellulose the activity of free enzyme was low. Evidence was obtained for the existence of two forms of endocellulase activity. One form adsorbed strongly to cellulose and was predominant in cultures low in cellulose. In cultures with a high cellulose content a non-adsorbable form of the enzyme was more abundant. The regulation of the appearance of free enzyme in relation to cellulose content and enzyme adsorption is discussed.
\end{abstract}

\section{INTRODUCTION}

Unsterile composted wheat straw is used as the culture medium for commercial production of the edible mushroom Agaricus bisporus. Some information is available about the nutrition of the mycelium of $\boldsymbol{A}$. bisporus in compost (Wood \& Fermor, 1981). The nutritional requirements for culturing the fungal mycelium in chemically defined media have also been determined (Treschow, 1944). Cellulose is one of the major constituents of compost (Gerrits et al., 1967) and represents an important potential carbon source for growth of $A$. bisporus. During growth and fruit body formation some of the cellulose in compost is utilized (Waksman \& Nissen, 1938; Gerrits, 1969). Turner et al. (1975) showed that extracts of mycelium-colonized compost possessed a cellulase activity which increased markedly during fruit body expansion. This cellulase activity which could have originated from other organisms present in the compost was later shown by Wood \& Goodenough (1977) to be produced by $A$. bisporus when grown and fruited axenically in sterilized compost. The regulatory mechanism of this increase in cellulase activity has yet to be determined.

Reese et al. (1950) were the first to determine the cellulolytic activity of the mycelium-free culture filtrate of several cellulolytic fungi. Since then many bacteria and fungi have been shown to degrade cellulose. Several higher basidiomycete fungi including the wood degrading brownrot and white-rot fungi produce one or more extracellular cellulases (Nilsson, 1974).

This study was carried out to examine the production and regulation of the endocellulase activity of $A$. bisporus cultures grown on defined media containing cellulose or other carbon sources. Agaricus bisporus was shown to excrete endocellulase when grown on various carbohydrate sources including soluble and insoluble celluloses. Laccase, an extracellular enzyme also released by the fungal mycelium, was used to estimate mycelial growth in cultures where direct measurement was not possible (Wood, 1979). The effect of the concentration of 
insoluble cellulose in the culture medium on cellulase production was examined. Major differences in the adsorption properties of cellulase from $A$. bisporus grown on different concentrations of insoluble cellulose were found. Evidence is presented for the role of catabolite repression in cellulase production by $A$. bisporus and of the existence of an extracellular cellulase inactivation system.

\section{METHODS}

Organism. Agaricus bisporus D621 of direct commercial origin was used.

Media and culture. Mycelium was grown in liquid medium prepared using Treschow's (1944) basal salts medium supplemented with various sole carbon sources; L-glutamic acid $[0.07 \%(\mathrm{w} / \mathrm{v})$; neutralized with $\mathrm{KOH}]$ as nitrogen source, and thiamin $\left(0.2 \mathrm{mg} \mathrm{l}^{-1}\right)$ and biotin $\left(0.02 \mathrm{mg} \mathrm{l}^{-1}\right)$ as essential vitamins. Sterile medium (50 $\mathrm{ml} \mathrm{in} \mathrm{a} 250 \mathrm{ml}$ conical flask) was inoculated with either two agar cubes $(2 \times 2 \times 2 \mathrm{~mm})$ cut from malt extract agar plate cultures (Wood, 1976) or with homogenized washed mycelium from a $1 \%(\mathrm{w} / \mathrm{v})$ glucose liquid culture resuspended in sterile basal medium (Fermor \& Wood, 1981). The cultures were grown at $25^{\circ} \mathrm{C}$ either static or shaken at 200 r.p.m. on a Gallenkamp orbital shaker. Growth and enzyme production was followed in static culture by sampling duplicate or triplicate cultures at suitable intervals. Culture filtrates and mycelium were collected by filtration through glass fibre discs $\left(5.5 \mathrm{~cm}\right.$ diam., Whatman GF/A). Mycelial dry weight was determined by drying the mycelium at $80^{\circ} \mathrm{C}$ to constant weight. Shaken cultures were sub-sampled by aseptically removing a small volume $(\sim 2 \mathrm{ml})$ of the culture fluid. The samples were clarified by centrifugation at $4000 \mathrm{~g}$ for $10 \mathrm{~min}$. Cellulase and laccase activities, soluble protein and soluble carbohydrate were determined in cell-free culture fluid.

For studying cellulase repression by glucose and cellobiose, A. bisporus was grown in Roux bottles in static culture containing carboxymethylcellulose (CM-cellulose, BDH no. 27649) as sole carbon source. Sterile medium $(250 \mathrm{ml})$ containing $1 \%(\mathrm{w} / \mathrm{v}) \mathrm{CM}$-cellulose was inoculated from a washed homogenized glucose grown culture. At $31 \mathrm{~d}$ when the rate of cellulase production was increasing exponentially (determined by a preliminary experiment), either glucose or cellobiose were added to the cultures. Each sugar was added aseptically dissolved in a small volume of sterile medium to give the following concentrations: $1,0.1,0.01,0.001 \%(\mathrm{w} / \mathrm{v})$. There were two replicates at each concentration for both sugars and two control cultures (no additions). Each culture was sampled for cellulase and laccase activity at suitable intervals. Samples of culture fluid were clarified by centrifugation.

Enzyme assays. One of the most commonly used substrates, CM-cellulose, is readily hydrolysed by most cellulolytic culture fluids although it may not be degraded by all the enzymes present in a cellulolytic culture (Shepherd et al., 1981). In this paper a viscometric method using CM-cellulose has been chosen. It is more sensitive than colorimetric methods of assay based on measuring liberated reducing end groups and is not affected by endogenous reducing substances.

Carboxymethylcellulase (1,4- $\beta$-D-glucan-4-glucanohydrolase; EC 3.2.1.4) activity was assayed in an Ubbelohde suspended level viscometer, size no. 3, maintained at $30^{\circ} \pm 0.05{ }^{\circ} \mathrm{C}$. The reaction mixture contained in a total volume of $20 \mathrm{ml}, 2 \%$ (w/v) CM-cellulose in $50 \mathrm{mM}$-acetic acid/NaOH buffer $(\mathrm{pH} 5.0)$ and culture fluid. The change in specific fluidity $\left(\eta_{\mathrm{sp}}^{-1}\right)$ with time was found to be linear over a wide range of enzyme activity and directly proportional to enzyme concentration. Cellulase activity was calculated in arbitrary units as $\eta_{\mathrm{sp}}^{-1} \mathrm{~s}^{-1}$.

Laccase was assayed polarographically according to Wood \& Goodenough (1977). One unit of laccase activity is defined as that amount of enzyme catalysing the consumption of $1 \mu \mathrm{mol} \mathrm{O}_{2} \mathrm{~min}^{-1}$. A factor of 102 laccase units per $\mathrm{g}$ dry weight of mycelium (Wood, 1979) enabled the equivalent mycelial dry weight to be calculated.

Cellulase adsorption. The adsorption of cellulase from culture filtrates was examined using a microcrystalline form of cellulose powder, Whatman CC41. The amount of cellulase adsorbed to different concentrations of cellulose was determined using the filtrate from a culture of $A$. bisporus grown on $0.05 \%(\mathrm{w} / \mathrm{v})$ Whatman $\mathrm{CC} 41$ cellulose. The filtrate $(2 \mathrm{ml})$ was mixed with fresh cellulose and incubated with occasional shaking at $25^{\circ} \mathrm{C}$. At $2 \mathrm{~h}$ the mixture was centrifuged and cellulase activity determined in the supernatant. In another experiment the adsorption of cellulase from filtrates of cultures grown on a range of cellulose concentrations was examined. Culture filtrates diluted to the same cellulase activity were shaken with $1 \%(\mathrm{w} / \mathrm{v})$ fresh cellulose in $50 \mathrm{~mm}$-acetate buffer at $25^{\circ} \mathrm{C}$. After $30 \mathrm{~min}$ the mixtures were centrifuged and cellulase assayed in the supernatants.

Cellulose determination. Residual insoluble cellulose in cultures was determined by the method of Updegraff (1969)

Carbohydrate determination. Soluble carbohydrate was determined by the phenol/sulphuric acid method (Dubois et al., 1956).

Protein determination. Protein in culture filtrates was estimated by the Lowry method.

Insoluble nitrogen determination. For analysis of total insoluble nitrogen, residues from culture filtrates were washed and digested with $0.5 \%(\mathrm{w} / \mathrm{v})$ selenium-sulphuric acid mixture and nitrogen determined in a Technicon auto analyser (O'Neill \& Webb, 1970). 


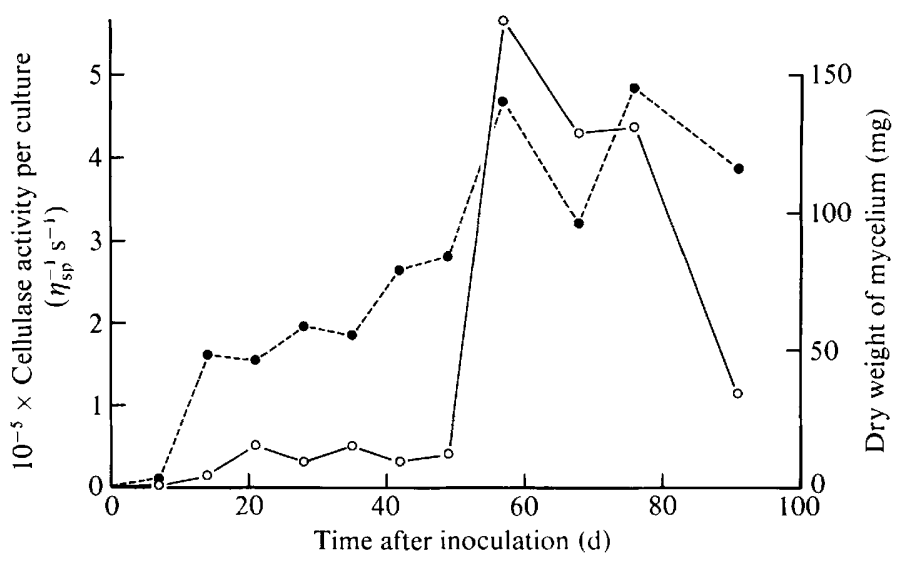

Fig. 1. Mycelial growth and cellulase production of $A$. bisporus in static liquid culture containing $2 \%$ $(w / v) \mathrm{CM}$-cellulose at $25^{\circ} \mathrm{C}: \mathrm{O}$, cellulase activity; $\odot$, dry weight of mycelium.

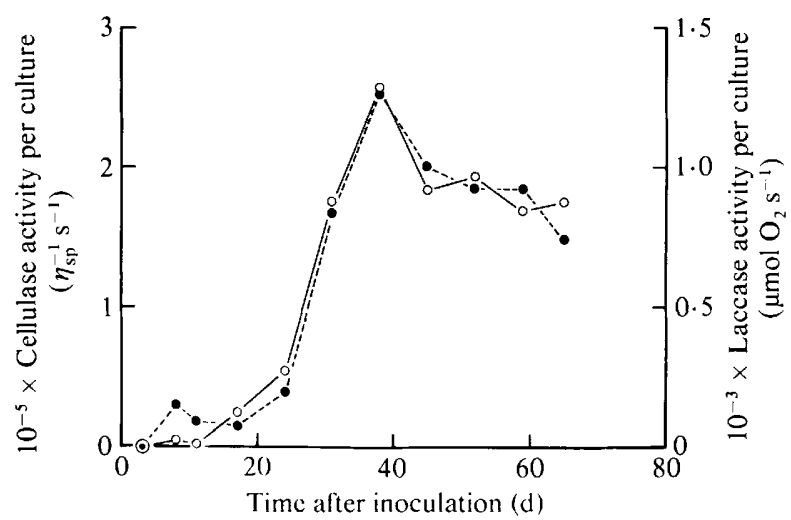

Fig. 2. Cellulase and laccase production during the growth of $A$. bisporus in static liquid culture containing $2 \%(\mathrm{w} / \mathrm{v})$ Whatman $\mathrm{CC} 41$ microcrystalline cellulose: $O$, cellulase activity;, laccase activity.

\section{RESULTS}

Growth and enzyme production on cellulose

The growth of $A$. bisporus mycelium and extracellular cellulase production were examined in static cultures grown on CM-cellulose (Fig. 1). After inoculation the mycelium grew steadily to reach a maximum at $57 \mathrm{~d}$. Although initially cellulase activity increased more slowly than mycelial growth, maximum enzyme activity coincided with maximum growth at $57 \mathrm{~d}$. At $91 \mathrm{~d}$, the enzyme activity had fallen to $20 \%$ of its highest value.

Cellulase production closely paralleled growth (determined by laccase activity) when the fungus was cultured on $2 \%(\mathrm{w} / \mathrm{v})$ of an insoluble microcrystalline form of cellulose powder, Whatman CC41 cellulose (Fig. 2). Cellulase activity reached a maximum at the end of exponential growth at $38 \mathrm{~d}$ and then declined steadily.

In shaken cultures containing $2 \%(\mathrm{w} / \mathrm{v}) \mathrm{CM}$-cellulose, maximum enzyme activity occurred earlier at $38 \mathrm{~d}$ and was approximately $30 \%$ of the highest activity produced in static culture. Growth and cellulase production were low in shaken or stirred cultures of $A$. bisporus grown on microcrystalline cellulose. In static conditions the fungus formed a spreading mat of mycelium which floated on the surface of the liquid medium. However, in shaken cultures the mycelium fragmented into small, dense, spherical clumps distributed throughout the bulk of the medium. 
Table 1. Effect of carbon source on mycelial growth and cellulase production of Agaricus bisporus

\begin{tabular}{|c|c|c|c|}
\hline Carbon source & $\begin{array}{l}\text { Dry weight } \\
\text { of mycelium } \\
\text { (mg) }\end{array}$ & $\begin{array}{c}10^{-6} \times \\
\text { Cellulase activity } \\
\text { per culture } \\
\left(\eta_{\mathrm{sp}}^{-1} \mathrm{~s}^{-1}\right)\end{array}$ & $\begin{array}{c}10^{-8} \times \\
\text { Specific activity } \\
(\mathrm{mg} \text { mycelium })^{-1} \\
\left(\eta_{\mathrm{sp}}^{-1} \mathrm{~s}^{-1}\right)\end{array}$ \\
\hline Whatman $\mathrm{CC} 41$ cellulose & $9.91^{*}$ & $33 \cdot 7$ & 340 \\
\hline Whatman floc & $1 \cdot 33^{*}$ & $28 \cdot 6$ & 2150 \\
\hline Solka floc & $5 \cdot 47^{*}$ & $24 \cdot 4$ & 446 \\
\hline Avicel & $4 \cdot 70^{*}$ & 6.53 & 139 \\
\hline CM-cellulose & $65 \cdot 9^{*}$ & $4 \cdot 57$ & 6.93 \\
\hline Cellulose acetate & $1 \cdot 30^{*}$ & 0.34 & 26 \\
\hline Cellophane & $1 \cdot 01$ & 0.02 & 2 \\
\hline Cellobiose & $72 \cdot 1$ & $5 \cdot 22$ & $7 \cdot 24$ \\
\hline Maltose & $105 \cdot 9$ & $2 \cdot 19$ & $2 \cdot 06$ \\
\hline Glucose & $186 \cdot 9$ & 1.93 & $1 \cdot 03$ \\
\hline Arabinose & $42 \cdot 6$ & 1.83 & $4 \cdot 30$ \\
\hline Sucrose & $147 \cdot 4$ & $1 \cdot 40$ & 0.948 \\
\hline Xylose & $46 \cdot 9$ & 0.84 & $1 \cdot 8$ \\
\hline Galactose & $49 \cdot 4$ & 0.57 & $1 \cdot 2$ \\
\hline Mannose & $73 \cdot 1$ & 0.40 & 0.55 \\
\hline Trehalose & $45 \cdot 5$ & $0 \cdot 16$ & $0 \cdot 35$ \\
\hline Glycerol & $13 \cdot 8$ & 0.06 & 0.4 \\
\hline Rhamnose & $28 \cdot 4$ & 0.04 & $0 \cdot 1$ \\
\hline Fructose & $136 \cdot 4$ & 0 & 0 \\
\hline Lactose & $35 \cdot 5$ & 0 & 0 \\
\hline Mannitol & $34 \cdot 8$ & 0 & 0 \\
\hline Ribose & $32 \cdot 5$ & 0 & 0 \\
\hline
\end{tabular}

\section{Induction of extracellular cellulase}

The fungus was cultured on a range of sole carbon sources to determine if extracellular cellulase formation was inducible or constitutive. Laccase activity was used to estimate mycelial growth in cultures containing cellulose and cellulose derivatives. The cellulase elaborated by $A$. bisporus appeared to be an inducible enzyme. Activities were highest when the organism was grown on Whatman CC41 cellulose, Whatman Floc and Solka Floc, cellulose substrates that are difficult to hydrolyse enzymically (Table 1). However, Avicel, another form of cellulose, induced less enzyme. The most easily attacked of the celluloses examined, CM-cellulose, also induced less cellulase but supported the maximum mycelial yield. Cellulase activity was low and $A$. bisporus grew poorly on cellulose acetate powder and cellophane.

Cellobiose was the most effective inducer of cellulase and gave good mycelial yields. Fructose gave good growth but no detectable enzyme in the culture filtrate. Glucose induced some cellulase and supported most growth.

\section{Effect of cellulose concentration on growth and cellulase production}

Cellulase excretion and growth were examined in cultures of $A$. bisporus containing different concentrations of cellulose. Whatman $\mathrm{CC} 41$ cellulose was used as sole carbon source in concentrations ranging from $0.015 \%$ to $18 \%(\mathrm{w} / \mathrm{v})$. The quantity of soluble cellulase activity appeared to be determined by the concentration of cellulose in the culture (Fig. 3). High cellulase activities were produced within a relatively narrow range of cellulose concentrations with the highest activity occurring at $0.1 \%(\mathrm{w} / \mathrm{v})$ cellulose. The level of enzyme declined to $0.3 \%$ of its maximum activity in cultures with $18 \%(\mathrm{w} / \mathrm{v})$ cellulose. Higher laccase activity and lower $\mathrm{pH}$ were found in cultures with greater cellulose concentration. Since actively growing cultures of $A$. bisporus usually show a fall in $\mathrm{pH}$, these results suggest that the fungus was able to grow well in high concentrations of cellulose. 


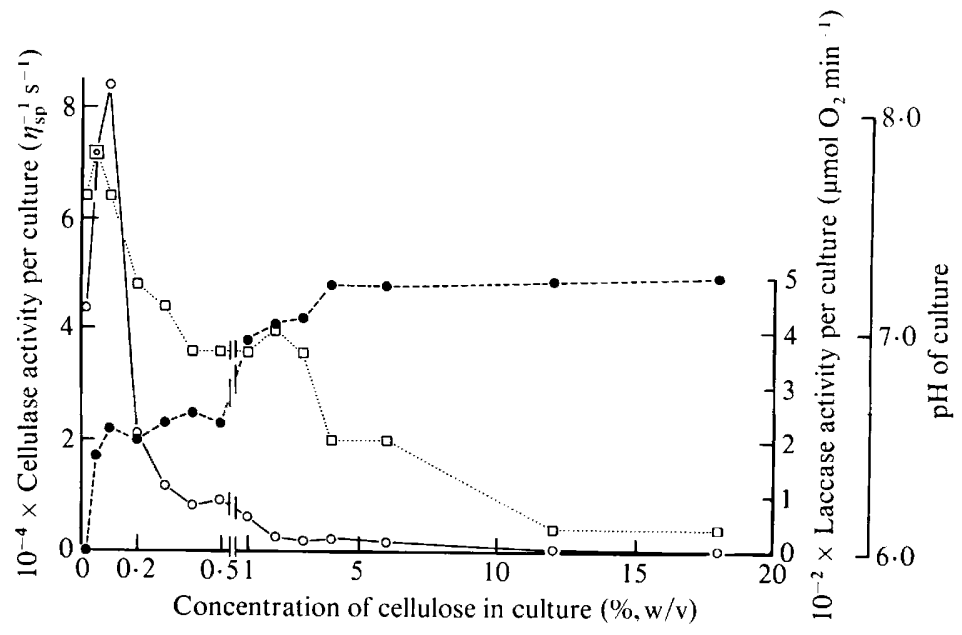

Fig. 3. Effect of concentration of Whatman $\mathrm{CC} 41$ cellulose on cellulase activity, laccase activity and $\mathrm{pH}$ in culture filtrates of $A$. bisporus. Cellulase activity $(\bigcirc)$; laccase activity $(O)$ and $\mathrm{pH}(\square)$ at 6 weeks.

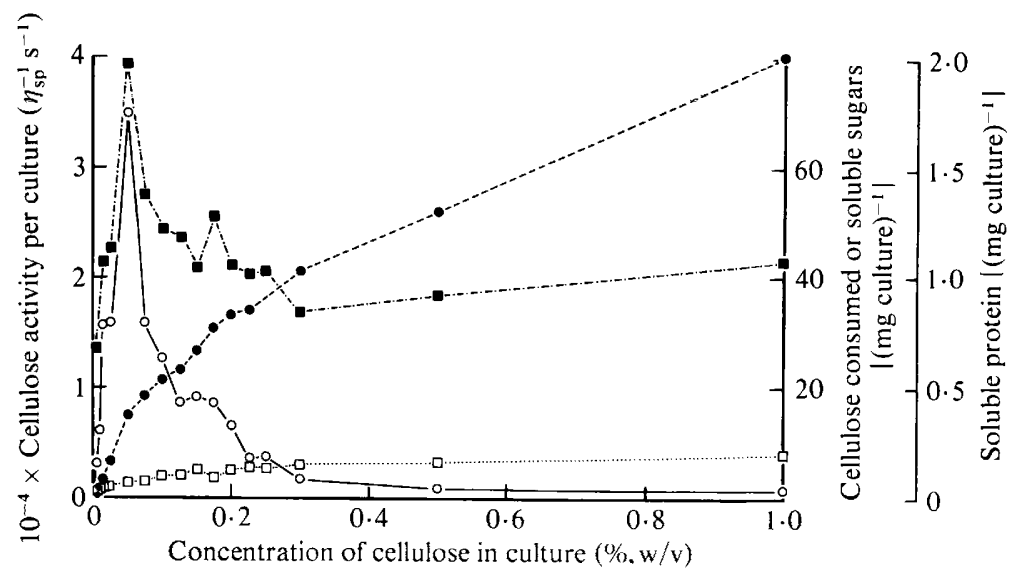

Fig. 4. Effect of concentration of Whatman CC41 cellulose in cultures of $A$. bisporus on soluble cellulase activity, protein and sugar concentration and on the consumption of cellulose. Cellulase activity $(O)$; soluble protein $(\square)$; soluble sugar $(\square)$ and cellulose consumption (O) at 6 weeks.

In another experiment $A$. bisporus was grown in cultures with cellulose concentrations ranging from $0.005 \%$ to $1 \%(\mathrm{w} / \mathrm{v})$ to examine cellulose consumption (Fig. 4). Maximum soluble enzyme was produced on $0.05 \%(\mathrm{w} / \mathrm{v})$ cellulose and less than $3 \%$ of the maximum level was found on $1 \%$ $(w / v)$ cellulose. Cellulose degradation was higher in cultures with higher initial cellulose concentrations although the level of soluble sugars was low in all cultures. Soluble protein concentration roughly paralleled cellulase activity between $0.005 \%$ and $0.2 \%(\mathrm{w} / \mathrm{v})$ cellulose and reached a steady level at cellulose concentrations above $0.2 \%(\mathrm{w}(\mathrm{v})$.

In a further experiment total insoluble nitrogen was determined in cultures containing between $0.2 \%$ and $10 \%(\mathrm{w} / \mathrm{v})$ cellulose. The nitrogen content $[$ mean $=575 \pm 65(\mathrm{~S} . \mathrm{E}$.) $\mu \mathrm{g} \mathrm{N}$ per culture] was similar for all cultures. This suggests that maximum fungal yield had been attained at $0.2 \%(\mathrm{w} / \mathrm{v})$ cellulose and was in reasonable agreement with estimates of growth using laccase.

\section{Cellulase adsorption}

An explanation for low soluble cellulase activity in cultures of $A$. bisporus grown on high concentrations of insoluble cellulose could be that some of the enzyme produced by $A$. bisporus 


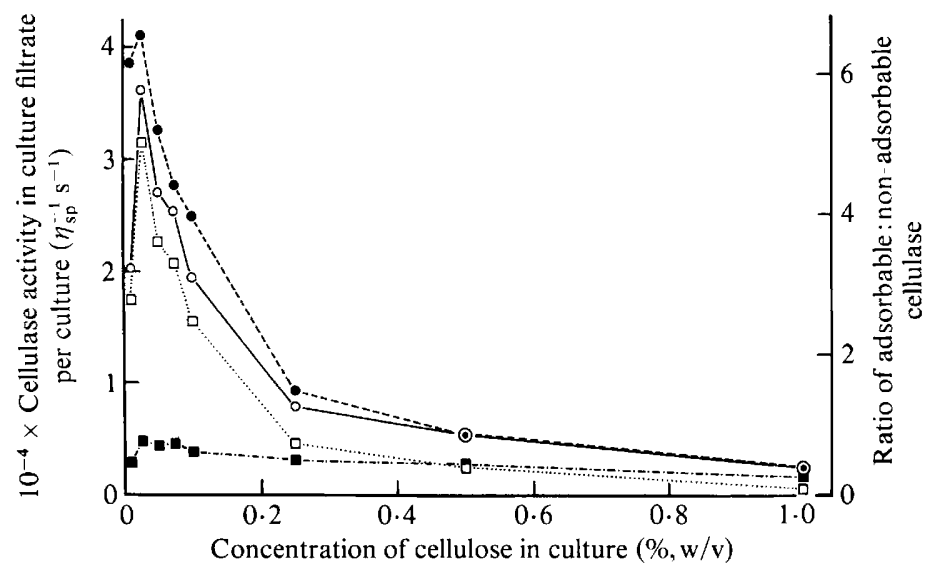

Fig. 5. Effect of cellulose concentration in cultures of $A$. bisporus upon the activity of soluble cellulase and on the adsorption properties of the enzyme. Cellulase activity $(O)$, adsorbable cellulase $(\square)$, nonadsorbable cellulase $(\square)$, and the ratio of adsorbable to non-adsorbable activity $(O)$ determined at 6 weeks.

was adsorbed on to the cellulose. Enzyme adsorption could also account for the differences in soluble protein. To test whether cellulase could be adsorbed the filtrate from a culture grown on $0.05 \%$ (w/v) Whatman CC41 cellulose was mixed with various amounts of fresh cellulose. The adsorption isotherm for cellulase was a rectangular hyperbola. Excess cellulose adsorbed $77 \%$ of the total activity, and half maximum adsorption occurred at $0.14 \%(\mathrm{w} / \mathrm{v})$ cellulose. Enzyme adsorption occurred rapidly $(<5 \mathrm{~min})$ and was enhanced at lower temperature and $\mathrm{pH}$.

Attempts to measure the quantity of enzyme adsorbed to cellulose in cultures were unsuccessful. Little enzyme was desorbed by using buffers of different $\mathrm{pH}$ and ionic strength. More enzyme was eluted with buffer containing CM-cellulose. Although the proportion of bound cellulase removed was unknown, more enzyme could be desorbed from residues of filtered cultures grown in high cellulose concentrations.

The amount of cellulase that could be adsorbed from cultures grown on different cellulose concentrations was investigated (Fig. 5). The ratio of adsorbable to non-adsorbable enzyme correlated closely with the amount of cellulose in the culture. Cultures with low cellulose concentrations had a higher proportion of adsorbable enzyme than those grown in high cellulose concentrations. Non-adsorbable cellulase activity was independent of cellulose concentration.

\section{Repression of cellulase production}

Glucose and cellobiose, possible products of cellulose breakdown, were tested for their ability to repress cellulase production by $A$. bisporus. Soluble CM-cellulose was selected as the inducer to avoid difficulties of enzyme adsorption. Figure 6 shows that glucose and cellobiose repress cellulase synthesis in the exponential phase of cellulase production. Increasing the amount of glucose added increased the degree of repression. Glucose at $0.1 \%$ and $1 \%(\mathrm{w} / \mathrm{v})$ produced an immediate and steady fall in enzyme activity. Cellobiose produced similar results except that $1 \%$ $(\mathrm{w} / \mathrm{v})$ cellobiose repressed cellulase formation less strongly than $0 \cdot 1 \%(\mathrm{w} / \mathrm{v})$ cellobiose.

\section{DISCUSSION}

Compared with many cellulolytic organisms $A$. bisporus grows slowly, typically reaching maximum growth yield in 5-6 weeks. However, like many cellulolytic organisms, cellulase production and growth occur simultaneously. A lag in the extracellular enzyme production was observed when the organism was grown on CM-cellulose. Since this substrate is initially easily degraded, only small amounts of enzyme would be required to provide mono- or disaccharides for growth. As the CM-cellulose becomes increasingly more difficult to hydrolyse, cellulase 


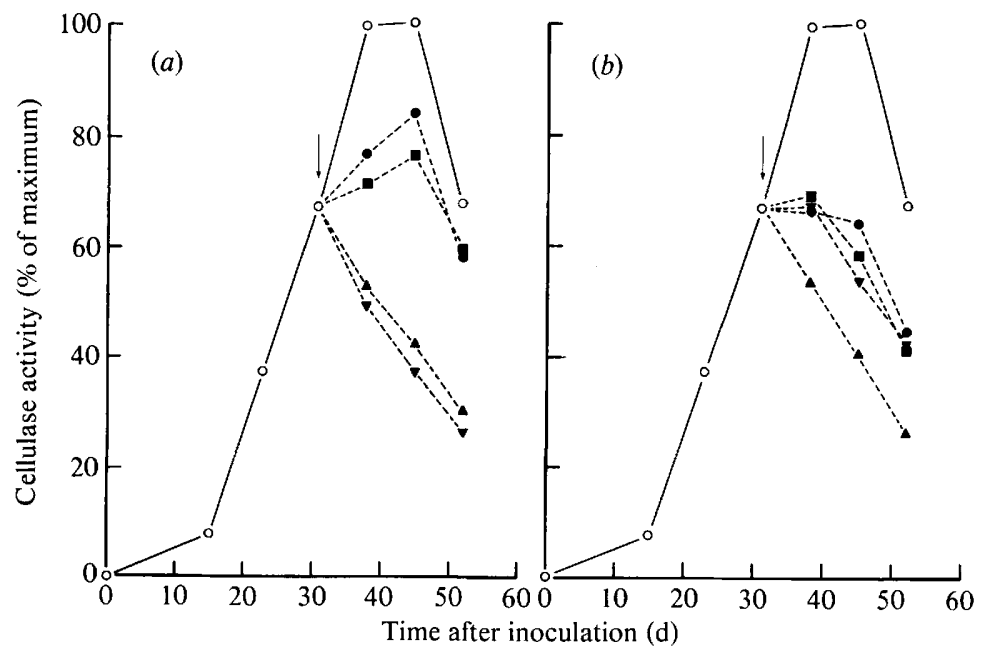

Fig. 6. Repression of production of cellulase by glucose (a) and cellobiose (b) in cultures of $A$. bisporus containing $1 \%(\mathrm{w} / \mathrm{v}) \mathrm{CM}$-cellulose. All additions were made at $31 \mathrm{~d}$ (arrows): $\mathrm{O}$, no addition (control); $0.001 \%(w / v) ; \boldsymbol{D}, 0.01 \%(w / v) ; \boldsymbol{\Delta}, 0.1 \%(w / v) ; \nabla, 1 \%(w / v)$

production must be greatly increased to maintain growth. A closer relationship between mycelial growth and cellulase production was found for microcrystalline cellulose. Growth and cellulase production are tightly coupled because growth and protein synthesis depend on cellulose hydrolysis. The close association found between extracellular cellulase production and growth in simple defined media also occurs in compost (Wood \& Goodenough, 1977). An increase in enzyme activity during fruit body expansion may be necessary if the mushroom is to utilize the cellulose in compost for growth.

Static cultures of $A$. bisporus grown in a thin liquid layer grew better and produced more cellulase than shaken or stirred cultures. Norkrans (1963) and King \& Smith (1973) reported similar observations for several cellulolytic fungi. It has been suggested that differences in culture conditions affect oxygenation within the culture. Studies on Phialophora malorum, a cellulolytic fungus that occurs in both filamentous and non-mycelial (unicellular) forms, showed that the latter existed exclusively in shaken cultures whereas mycelium predominated in stationary cultures (Berg, 1978). The normal mat of mycelial growth of $A$. bisporus in static culture changed radically to give fragmented growth in shaken cultures. Shaken or stirred cultures containing microcrystalline cellulose produced less growth and enzyme than those containing CM-cellulose. This may have been due either to the more abrasive property of the microcrystalline form of cellulose or to there being less long-term contact between mycelium and substrate.

The influence of carbon source on the growth of $A$. bisporus and cellulase biosynthesis is characteristic of white-rot fungi. In this group of organisms cellulose induces high levels of cellulase whereas simple sugars, although able to support good growth, induce little or no enzyme formation (Highley, 1973). Differences in the amount of cellulase induced by various types of cellulose may have been due to differences in adsorption of the enzyme to cellulose. Cellobiose is reported to be a cellulase inducer in several fungi (Mandels \& Reese, 1960). It is, however, questionable whether cellobiose is a true inducer since several workers have demonstrated that cellobiose can inhibit as well as induce cellulase biosynthesis (Eriksson \& Hamp, 1978). The same is also true for glucose. The question of whether glucose or cellobiose is an inducer or inhibitor depends on the concentration of the sugar.

In common with other cellulolytic fungi $A$. bisporus utilizes cellulose for growth and regulates cellulase biosynthesis by feedback inhibition to prevent overproduction of soluble sugars. The sensitivity of the fungus to both glucose and cellobiose may be related to its slow growth rate. In 
comparison with $1 \%$ glucose, cellobiose at the same concentration repressed cellulase less effectively. An explanation for this may be that cellobiose has an inducing effect at this concentration. Catabolite repression can cause a decrease or cessation of enzyme production but does not explain why the enzyme activity decreases. Since cellulase is a relatively stable enzyme, we suggest that the fungus has a mechanism for destroying or inactivating cellulase. Further work will be necessary to examine this suggestion. Other examples are known in this fungus and others of extracellular systems responsible for inactivation of excreted enzymes (Wood, 1980; Friebe \& Holldorf, 1975).

Since cellulose is insoluble and needs to be hydrolysed before it can be utilized the question arises as to how the organism recognizes cellulose. In the present study, cellulase activity was not apparently produced constitutively. However, this does not preclude the possibility that the fungus excretes enzyme protein below detection limits. Small amounts of sugar would be released from any cellulose present and this would induce further enzyme production.

One of the most important factors regulating cellulase production is cellulose concentration. For $A$. bisporus the production of soluble cellulase activity is critically dependent on cellulose concentration with an optimum between 0.05 and $0.1 \%(\mathrm{w} / \mathrm{v})$ cellulose. Mandels \& Weber (1969) reported that optimum cellulose concentrations for cellulase production by Trichoderma viride varied between $0.5 \%$ and $1 \%(\mathrm{w} / \mathrm{v})$ depending on composition of the medium, and that higher cellulose concentrations were inhibitory. For Sporotrichum thermophile cellulase production was greatest in $1 \%(\mathrm{w} / \mathrm{v})$ cellulose (Coutts \& Smith, 1976).

The results show that cellulase adsorption may account for the pattern of cellulase activities observed when $A$. bisporus is grown on different cellulose concentrations. Adsorption of cellulase is a widely occurring phenomenon amongst cellulolytic fungi (Ghose \& Bisaria, 1979) and is a prerequisite for cellulose hydrolysis. In addition to cellulase other excreted proteins may be adsorbed to cellulose (Hagerdal et al., 1978).

As far as the authors are aware this is the first report of differences in the adsorption properties of cellulase produced on different concentrations of cellulose. Adsorbable and nonadsorbable forms of cellulase appear to be produced by the fungus in proportions that depend upon the concentration of cellulose in the culture. The reasons for $A$. bisporus producing more than one type of enzyme activity are uncertain. An enzyme which adsorbs strongly would allow more complete hydrolysis of the available cellulose. An organism producing enzymes with a range of specificities towards various celluloses would be able to regulate the proportion of each enzyme according to the type and quantity of cellulose present in the environment.

When $A$. bisporus is grown on compost in solid culture a high level of extractable endocellulase activity is produced at the fruiting stage. However, if grown on an equivalent concentration of pure cellulose $A$. bisporus produces only low levels of soluble enzyme. Free cellulase activity may be higher in compost either because of qualitative and quantitative differences in individual cellulases or because less enzyme is adsorbed in compost. Total extracellular cellulase activity in a culture can only be determined if the amount of enzyme adsorbed to cellulose is known. One approach to this problem is the use of immunochemical techniques to quantify each enzyme protein. It would also be of interest to know which enzymes are responsible for the increase in cellulase activity during fruiting.

For a better understanding of how simple sugars are released from cellulose in compost more information is required on the mechanism of action of each cellulase component. This paper describes how endocellulase activity in crude culture filtrates is related to growth of $A$. bisporus. However, most cellulolytic organisms appear to hydrolyse native cellulose by the synergistic action of several enzymes including endocellulases, exocellulases and $\beta$-glucosidases (Bisaria $\&$ Ghose, 1981). Wood \& McCrae (1978) have shown that Trichoderma viride produces several endocellulases which hydrolyse CM-cellulose with different degrees of randomness. It has yet to be determined whether an exocellulase enzyme is produced by $A$. bisporus and whether the endocellulase activity observed represents more than one enzyme.

The authors would like to thank Mr Stephen Matcham for his skilled technical assistance. 


\section{REFERENCES}

BERG, B. (1978). Cellulose degradation and cellulase formation by Phialophora malorum. Archives of Microbiology 118, 61-65.

BisARIA, V. S. \& GHose, T. K. (1981). Biodegradation of cellulosic materials: substrates, microorganisms, enzymes and products. Enzyme and Microbial Technology 3, 90-104.

CoutTs, A. D. \& Sмiтh, R. E. (1976). Factors influencing the production of cellulases by Sporotrichum thermophile. Applied and Environmental Microbiology 31, 819-825.

Dubois, M., Gilles, K. A., Hamilton, J. K., Rebers, P. A. \& Smith, F. (1956). Colorimetric method for determination of sugars and related substances. Analytical Chemistry 28, 350-356.

ERIKSSON, K-E. \& HAMP, S. G. (1978). Regulation of endo-1,4- $\beta$-glucanase production in Sporotrichum pulverulentum. European Journal of Biochemistry $\mathbf{9 0}$, $183-190$

FERMOR, T. R. \& WoOD, D. A. (1981). Degradation of bacteria by Agaricus bisporus and other fungi. Journal of General Microbiology 126, 377-387.

Friebe, B. \& Holldorf, A. W. (1975). Control of extracellular $\beta$-1,3-glucanase activity in a basidiomycete species. Journal of Bacteriology 122, 818-825.

GerRITS, J. P. G. (1969). Organic compost constituents and water utilized by the cultivated mushroom during spawn run and cropping. Mushroom Science 7, 111-126.

Gerrits, J. P. G., Bels-Koning, H. C. \& Muller, F. M. (1967). Changes in compost constituents during composting, pasteurisation and cropping. Mushroom Science 6, 225-243.

Ghose, T. K. \& Bisaria, V. S. (1979). Studies on the mechanism of enzymatic hydrolysis of cellulosic substances. Biotechnology and Bioengineering 21, $131-146$

Hagerdal, B. G. R., Ferchak, J. D. \& Pye, E. K. (1978). Cellulolytic enzyme system of Thermoactinomyces $\mathrm{sp}$. grown on microcrystalline cellulose. Applied and Environmental Microbiology 36, 606-612.

Highley, T. L. (1973). Influence of carbon source on cellulase activity of white-rot and brown-rot fungi. Wood and Fiber 5, 50-58.

KING, N. J. \& SMITH, G. A. (1973). A cellulolytic enzyme from the wood-destroying basidiomycete B531. Part 1. Growth of the fungus and enzyme production. International Biodeterioration Bulletin 9 , 87-90.

MANDELS, M. \& ReESE, E. T. (1960). Induction of cellulase in fungi by cellobiose. Journal of Bacteriology 79, 816-826.

MANDELS, M. \& WebER, J. (1969). The production of cellulases. In Cellulases and their Applications, pp. 391-414. Edited by G. J. Hajny \& E. T. Reese. Washington D.C.: American Chemical Society.

NiLsson, T. (1974). Comparative study on the celluloly- tic activity of white-rot and brown-rot fungi. Material und Organismen 9, 173-198.

NoRKRANS, B. (1963). Influence of some cultural conditions on fungal cellulase production. Physiologia plantarum 16, 11-19.

O'Neill, J. V. \& WeBB, R. A. (1970). Simultaneous determination of nitrogen, phosphorus and potassium in plant material by automatic methods. Journal of the Science of Food and Agriculture 21, 217219.

Reese, E. T., Siu, R. G. H. \& Levinson, H. S. (1950). The biological degradation of soluble cellulose derivatives and its relationship to the mechanism of cellulose hydrolysis. Journal of Bacteriology 59, 485497.

Shepherd, M. G., Tong, C. C. \& Cole, A. L. (1981). Substrate specificity and mode of action of the cellulases from the thermophilic fungus Thermoascus aurantiacus. Biochemical Journal 193, 67-74.

Treschow, C. (1944). Nutrition of the cultivated mushroom. Dansk botanisk Arkiv 11, 1-180.

Turner, E. M., Wright, M., Ward, T., Osborne, D. J. \& SelF, R. (1975). Production of ethylene and other volatiles and changes in cellulase and laccase activities during the life cycle of the cultivated mushroom Agaricus bisporus. Journal of General Microbiology 91, 167-176.

UPDEGRAFF, D. M. (1969). Semimicro determination of cellulose in biological materials. Analytical Biochemistry 32, 420-424.

W AKSMAN, S. A. \& NisSEN, W. (1938). On the nutrition of the cultivated mushroom Agaricus campestris, and the chemical changes brought about by this organism in the manure compost. American Journal of Botany 19, 514-537.

Wood, D. A. (1976). Primordium formation in axenic cultures of Agaricus bisporus (Lange) Sing. Journal of General Microbiology 95, 313-323.

Wood, D. A. (1979). A method for estimating biomass of Agaricus bisporus in a solid substrate, composted wheat straw, Biotechnology Letters 6, 255-260.

WoOD, D. A. (1980). Inactivation of extracellular laccase during fruiting of Agaricus bisporus. Journal of General Microbiology 117, 339-345.

WOOD, D. A. \& FERMOR, T. R. (1981). Nutrition of Agaricus bisporus in compost. Mushroom Science 11, 63-71.

WOOD, D. A. \& Goodenough, P. W. (1977). Fruiting of Agaricus bisporus. Changes in extracellular enzyme activities during growth and fruiting. Archives of Microbiology 114, 161-165.

Wood, T. M. \& MCCRAE, S. I. (1978). The cellulase of Trichoderma koningii. Purification and properties of some endoglucanase components with special reference to their action on cellulose when acting alone and in synergism with the cellobiohydrolase. Biochemical Journal 171, 61-72. 